\title{
Anticardiolipin antibodies do not mediate macrovascular complications of type 2 diabetes
}

\author{
Caroline Eickhoff Copetti ${ }^{1}$, Myriam Perreynoud ${ }^{2}$, Melissa Claudia Bisi ${ }^{1}$, Henrique Luiz Staub ${ }^{{ }^{*}}$ \\ ${ }^{1}$ Rheumatology Department, São Lucas Hospital, Faculty of Medicine, Pontifical Catholic University of Rio Grande do Sul (PUCRS), \\ Porto Alegre, Brazil \\ ${ }^{2}$ Clinical Pathology Laboratory, São Lucas Hospital, PUCRS, Porto Alegre, Brazil \\ Email: "henriquestaub@terra.com.br
}

Received 7 September 2011; revised 11 November 2011; accepted 22 November 2011

\begin{abstract}
The relationship of anticardiolipin antibodies (ACA), markers of the antiphospholipid syndrome, with vascular complications of diabetes mellitus is polemic. This cross-sectional study assessed the frequency of IgG, IgM, and IgA ACA in type 2 diabetics with and without history of vascular events for the last 5 years, and in healthy controls. ACA were detected by enzyme immunoassay. A total of 73 type 2 diabetics (33 with history of vascular events) and 54 healthy controls were tested. Most diabetics were female $(p=$ $0.003)$, and older than controls $(p<0.001)$. Mean duration of disease was 10 years. The prevalence of a positive ACA test was $7.4 \%$ in controls and $9.5 \%$ in diabetics $(p=0.910)$. Comparison of healthy controls and diabetics with and without history of macrovasculopathy, after adjusting for gender and age, showed no significant differences as to the presence of ACA $(p>0.09)$. ACA positivity rates were also similar when diabetics with and without history of vasculopathy were compared $(p>0.47)$. After adjusting for gender, age, hypertension, and smoking status, a weak but statistically insignificant association between IgM ACA and diabetics with vasculopathy was found (adjusted OR 2.7; 95\% CI 0.2 - 34.2; $p=0.441$ ). Overall, levels of IgG $(r=0.25 ; p=0.005)$ and IgM $(r=0.23$; $=0.010$ ) ACA were associated with increasing age. In short, the frequency of a positive ACA test in type 2 diabetics (with or without previous macrovasculopathy) was not significant as compared to healthy controls. There was no association of ACA with vascular events in patients with type 2 diabetes.
\end{abstract}

Keywords: Anticardiolipin Antibodies; Type 2 Diabetes Mellitus; Myocardial Infarction; Cerebrovascular Infarction

\footnotetext{
"Corresponding author.
}

Anticardiolipin antibodies (ACA), as well as the lupus anticoagulant and antibodies to beta2-glycoprotein (beta2gPI), are classical markers of the antiphospholipid syndrome (APS) [1]. The relationship of ACA with vascular complications of diabetes is rather unclear.

This cross-sectional study assessed the frequency of IgG, IgM, and IgA ACA in type 2 diabetics [2] with and without history of macrovascular events (myocardial and/or cerebral infarction) for the last 5 years, and in healthy controls. ACA were detected by enzyme immunoassay (ORGENTEC Diagnostika GmbH-Anti-Cardiolipin). Titers were considered as positive when above 10 GPL for IgG ACA, 10 MPL for IgM ACA, and 7 units for IgA ACA [3]. The study was approved by the local ethics committee.

Chi-square analysis were used for comparison of categorical variables, and the Student's t test was used for comparison of continuous variables. A level of 5\% (p $<0.05$ ) was considered significant. Odds ratios (OR) with 95\% confidence intervals (95\% CI) were calculated for univariate analysis. Logistic regression with 95\% CI was performed to adjust the effects of gender, age, hypertension [4], and current smoking [5] in the OR. When needed, Agresti correction was employed to obtain nonadjusted OR. To co-relate quantitative variables, the Pearson coefficient was utilized. All analyses used procedures of the SPSS for Windows, version 11.5, Chicago, IL.

A total of 73 type 2 diabetics (33 with history of vascular events) and 54 healthy controls were tested. Most diabetics were female $(p=0.003)$, and older than controls $(\mathrm{p}<0.001)$. Mean duration of disease was 10 years. The prevalence of a positive ACA test (any isotype) was $7.4 \%$ in controls (5.6\% IgA ACA) and 9.5\% in diabetics $(\mathrm{p}=0.910)$.

Comparison of healthy controls and diabetics with or without history of macrovasculopathy, after adjusting for gender and age, showed no significant differences in ACA positivity $(\mathrm{p}>0.09$ ). ACA frequency rates were 
also similar when diabetics with and without recent history of vascular events were compared ( $p>0.47$ ).

Females significantly predominated in diabetics without vasculopathy as compared to diabetics with previous vascular events. After adjusting for gender, age, hypertension, and smoking status, a weak but statistically insignificant association of IgM ACA and diabetics with vasculopathy was found. These data can be seen in Table 1.

Overall, levels of IgG ( $r=0.25 ; \mathrm{p}=0.005)$ and IgM ( $\mathrm{r}$ $=0.23 ; \mathrm{p}=0.010$ ) ACA related to increasing age.

Type 2 diabetes comprise an independent risk factor for atherosclerotic disease. The etiopathogenesis of the micro and macrovascular complications of type 2 diabetes are not fully understood. Macrovascular obstructions affecting the coronary and cerebral arteries are the main cause of mortality in diabetics [6,7]. ACA and endothelial dysfuncion might be synergistic for vasculopathy in insulin-dependent diabetes [8].

For the last decade, we have documented a defined association of IgA anti-beta2-gpI antibodies with cerebral ischemia [9], coronary disease [10], carotid disease [11], and peripheral artery disease [12]. Only in one of these studies [12], IgA ACA associated with the outcome. More recently, we demonstrated an association of the IgA anti-beta2-gpI antibody with metabolic syndrome; once more, the ACA prevalence was low [13]. We therefore infer that ACA do not relate to acute or chronic atherosclerotic disease, nor to metabolic syndrome. The relationship of ACA with type 2 diabetes and diabetic vasculopathy had not been so far evaluated in our research center.

In the current study, ACA positivity was similar in controls and type 2 diabetics (7.4\% and 9.5\%, respectively). There was no statistical difference as to the ACA prevalence in the two groups. The frequency of IgA ACA in our healthy controls (5.6\%) was quite impressive, and this is an issue to be further addressed. Differently from our data, Hendra et al reported a significant frequency of IgG ACA in diabetics with or without coronary disease [14]. Gargiulo et al. described elevated levels of IgA anti-phosphatidylethanolamine, but not ACA, in type 1 or 2 diabetics as compared to controls [15]. Similarly to our findings, the prevalence of ACA in non-complicated diabetes was irrelevant in another previous study [16].

When our two groups of diabetics were compared, a weak association of IgM ACA with complicated diabetes was suggested by the adjusted OR, but this finding was statistically insignificant. Of interest, the frequency of ACA in type 1 or 2 diabetics with macroangiopathy and nephropathy was higher as compared to patients with non-complicated or well-controlled disease [16]. Another group of authors reported, in 1989, an increased positivity for IgG and IgA ACA in type 2 diabetics with macrovascular disease [17]. As seen, data concerning prevalence of ACA in diabetes are incongruent.

We herein documented a significant correlation of IgG and IgM ACA with increasing age. This is in accordance with the study by Fields et al., whereby IgG and IgM ACA were detected in $12 \%$ of the healthy elderly and in $2 \%$ of younger adults [18]. As opposed to that, ACA positivity in the elderly was reported to be insignificant and similar to younger populations [19].

In general terms, our results pointed to a insignificant positivity for ACA in type 2 diabetes. A low prevalence of ACA was seen in both complicated or non-complicated diabetic populations. These data, although limited by the small sample, do not favour a pathogenetic role for ACA in type 2 diabetes and diabetic macrovasculopathy. Our findings are corroborated by those reported by Tarkun et al., which desvinculated ACA from vascular complications of type 2 diabetes [20].

In summary, the frequency of a positive ACA test in type 2 diabetes (complicated or not by macrovasculo-

Table 1. Clinical variables and frequency of anticardiolipin antibodies (ACA) in both group of diabetics.

\begin{tabular}{|c|c|c|c|c|c|c|}
\hline & $\begin{array}{c}\text { Diabetics with } \\
\text { vascular event } n=33\end{array}$ & $\begin{array}{c}\text { Diabetics without } \\
\text { vascular event } n=40\end{array}$ & $\mathrm{p}$ & $\begin{array}{l}\text { Non-adjusted OR } \\
\quad(95 \% \text { CI })\end{array}$ & $\begin{array}{l}\text { Adjusted OR }{ }^{* * *} \\
\quad(95 \% \mathrm{CI})\end{array}$ & $\mathrm{p}$ \\
\hline Age (years) ${ }^{\dagger}$ & $68.2( \pm 10.65)$ & $65.9( \pm 9.1)$ & $0.331^{\ddagger}$ & $1.0(0.9-1.1)$ & NC & NC \\
\hline Females & $16(48.5 \%)$ & $33(82.5 \%)$ & $0.005^{*}$ & $0.2(0.1-0.6)$ & NC & NC \\
\hline Hypertension & 29 (87.9\%) & 33 (82.5\%) & $0.744^{*}$ & $1.5(0.4-5.8)$ & NC & NC \\
\hline History of smoking & $8(24.2 \%)$ & $11(27.5 \%)$ & $0.962^{*}$ & $0.8(0.3-2.4)$ & NC & NC \\
\hline IgG ACA positive & 0 & $1(2.5 \%)$ & $0.999^{*}$ & $0.6(0.05-6.8)^{* *}$ & $\mathrm{NC}$ & NC \\
\hline IgM ACA positive & $3(9.1 \%)$ & $1(2.5 \%)$ & $0.475^{*}$ & $3.9(0.4-39.4)$ & $2.7(0.2-34.2)$ & 0.441 \\
\hline IgA ACA positive & 0 & 2 (5.0\%) & $0.560^{*}$ & $0.4(0.04-3.9)^{* *}$ & NC & NC \\
\hline
\end{tabular}

n: Sample number; ${ }^{\dagger}$ SD: Standard deviation; ${ }^{\ddagger}$ Student t test; ${ }^{*}$ Chi-square test; ${ }^{* *}$ Agresti correction; ${ }^{* * *}$ Adjustment for sex, age, hypertension and smoking; NC: Non-calculated. 
pathy) did not significantly differ from controls. There was no association of ACA with vascular events in patients with type 2 diabetes. ACA do not appear to be relevant in the pathogenesis of vascular complications of type 2 diabetes.

\section{REFERENCES}

[1] Miyakis, S., Lockshin, M.D., Atsumi, T., Branch, D.W., Brey, R.L., Cervera, R., et al. (2006) International consensus statement on an update of the classification criteria for definite antiphospholipid syndrome (APS). Journal of Thrombosis and Haemostasis, 4, 295-306. doi:10.1111/j.1538-7836.2006.01753.x

[2] Grundy, S.M., Cleeman, J.I., Daniels, S.R., Donato, K.A., Eckel, R.H., Franklin, B.A., et al. (2005) Diagnosis and management of the metabolic syndrome. An American Heart Association/National Heart, Lung, and Blood Institute Scientific Statement. Executive summary. Cardiology in Review, 13, 322-327.

[3] Gharavi, A.E., Harris, E.N., Asherson, R.A. and Hughes, G.R. (1987) Anticardiolipin antibodies: Isotype distribution and phospholipid specificity. Annals of the Rheumatic Diseases, 46, 1-6. doi:10.1136/ard.46.1.1

[4] Chobanian, A.V., Bakris, G.L., Black, H.R., Cushman, W.C., Green, L.A., Izzo, J.L. Jr., et al. (2003) The seventh report of the Joint National Committee on Prevention, Detection, Evaluation, and Treatment of High Blood Pressure: The JNC 7 report. Journal of the American Medical Association, 289, 2560-2572. doi:10.1001/jama.289.19.2560

[5] Filozof, C., Fernandez Pinilla, M.C. and Fernández-Cruz, A. (2004) Smoking cessation and weight gain. Obesity Research, 5, 95-103. doi:10.1111/j.1467-789X.2004.00131.X

[6] King, H., Aubert, R.E. and Herman, W.H. (1998) Global burden of diabetes, 1995-2025: Prevalence, numerical estimates, and projections. Diabetes Care, 21, 1414-1431. doi:10.2337/diacare.21.9.1414

[7] Kannel, W.B. and McGee, D.L. (1979) Diabetes and cardiovascular disease. The Framingham study. Journal of the American Medical Association, 241, 2035-2038. doi:10.1001/jama.1979.03290450033020

[8] Ciarla, M.V., Bocciarelli, A., Di Gregorio, S., Tordi, A., Cotroneo, P., Marra, G., et al. (2001) Autoantibodies and endothelial dysfunction in well-controlled, uncomplicated insulin-dependent diabetes mellitus patients. Atherosclerosis, 158, 241-246. doi:10.1016/S0021-9150(01)00440-3

[9] Staub, H.L., Norman, G.L., Crowther, T., Da Cunha, V.R., Polanczyk, A., Bohn, J.M., et al. (2003) Antibodies to the atherosclerotic plaque components beta2-glycoprotein I and heat-shock proteins as risk factors for acute cerebral ischemia. Arquivos De Neuro-Psiquitria, 61, 757763. doi:10.1590/S0004-282X2003000500010
[10] Ranzolin, A., Bohn, J.M., Norman, G.L., Manenti, E., Bodanese, L.C., Von Muhlen, C.A., et al. (2004) Antibeta2-glycoprotein I antibodies as risk factors for acute myocardial infarction. Arquivos Brasileiros de Cardiologia, 83, 141-144.

[11] Recuero, M.L., Silva, J.B., Norman, G.L., Von Muhlen, C.A. and Staub, H.L. (2007) IgA antibodies to beta2glycoprotein I and carotid disease. Israel Medical Association Journal, 9, 495-496.

[12] Franck, M., Staub, H.L., Petracco, J.B., Norman, G.L., Lassen, A.J., Schiavo, N., et al. (2007) Autoantibodies to the atheroma component beta2-glycoprotein I and risk of symptomatic peripheral artery disease. Angiology, 58, 295-302. doi:10.1177/0003319707302493

[13] Krás Borges, R., Bodanese, L., Von Mühlen, C., Repetto, G., Viehe, M., Norman, G., et al. (2011) Anti-beta2glycoprotein I autoantibodies and metabolic syndrome. Arquivos Brasileiros de Cardiologia, 96, 272-276.

[14] Hendra, T.J., Baguley, E., Harris, E.N., Khamashta, M.H., Trembath, R.C., Hughes, G.R., et al. (1989) Anticardiolipin antibody levels in diabetic subjects with and without coronary artery disease. Postgraduate Medical Journal, 65, 140-143. doi:10.1136/pgmj.65.761.140

[15] Gargiulo, P., Goldberg, J., Romani, B., Schiaffini, R., Ciampalini, P., Faulk, W.P., et al. (1999) Qualitative and quantitative studies of autoantibodies to phospholipids in diabetes mellitus. Clinical \& Experimental Immunology, 118, 30-34. doi:10.1046/j.1365-2249.1999.01014.X

[16] Galtier-Dereure, F., Biron, C., Vies, M., Bourgeois, V., Schved, J.F. and Bringer, J. (1998) Vascular complications of diabetes mellitus: What role for phospholipidbinding antibodies? Lupus, 7, 469-474. doi:10.1191/096120398678920488

[17] Triolo, G., Giardina, E., Scarantino, G., Seddio, G. and Bompiani, G. (1989) Detection of anti-phospholipid (cardiolipin, phosphatidylserine) antibodies in the serum of patients with non insulin-dependent (type 2) diabetes mellitus and macroangiopathy. Coexistence of antiplatelet reactivity. Diabetes Research, 10, 63-67.

[18] Fields, R.A., Toubbeh, H., Searles, R.P. and Bankhurst, A.D. (1989) The prevalence of anticardiolipin antibodies in a healthy elderly population and its association with antinuclear antibodies. Journal of Rheumatology, 16, 623-625.

[19] Chakravarty, K.K., Gray, R.E., Webley, M., Byron, M.A. and Wozniak, J. (1991) Prevalence of anticardiolipin antibodies in the elderly British population. Postgraduate Medical Journal, 67, 358-361. doi:10.1136/pgmj.67.786.358

[20] Tarkun, I., Hacihanefioglu, A., Tarkun, P., Cetinarslan, B. and Canturk, Z. (2005) Anticardiolipin and anti-beta2 glycoprotein I antibody concentrations in patients with type 2 diabetes mellitus. Diabetes Research and Clinical Practice, 68, 181-187. doi:10.1016/j.diabres.2004.09.005 